\title{
Are Excise Taxes on Beverages Fully Passed through to Prices? The Danish Evidence
}

Bergman, U. Michael; Hansen, Niels Lynggård

Document Version

Final published version

\section{Published in:}

Finanzarchiv

DOI:

10.1628/fa-2019-0010

Publication date:

2019

\section{License}

Unspecified

Citation for published version (APA):

Bergman, U. M., \& Hansen, N. L. (2019). Are Excise Taxes on Beverages Fully Passed through to Prices? The Danish Evidence. Finanzarchiv, 75(4), 323-356. https://doi.org/10.1628/fa-2019-0010

Link to publication in CBS Research Portal

\section{General rights}

Copyright and moral rights for the publications made accessible in the public portal are retained by the authors and/or other copyright owners and it is a condition of accessing publications that users recognise and abide by the legal requirements associated with these rights.

Take down policy

If you believe that this document breaches copyright please contact us (research.lib@cbs.dk) providing details, and we will remove access to the work immediately and investigate your claim. 


\section{Are Excise Taxes on Beverages Fully Passed through to Prices? The Danish Evidence}

\section{U. Michael Bergman and Niels Lynggård Hansen}

Journal article (publisher's version)

\section{Please cite this article as:}

Bergman, U. M., \& Hansen, N. L. (2019). Are Excise Taxes on Beverages Fully Passed through to Prices? The Danish Evidence. Finanzarchiv, 75(4), 323-356. https://doi.org/10.1628/fa-2019-0010 DOl: https://doi.org/10.1628/fa-2019-0010

Uploaded in accordance with Mohr Siebeck's Public Access Policy: https://www.mohrsiebeck.com/en/public-access-policy

Uploaded to CBS Research Portal: August २०२० 


\title{
Are Excise Taxes on Beverages Fully Passed Through to Prices? The Danish Evidence
}

\author{
U. Michael Bergman and Niels Lynggård Hansen*
}

Received 26 June 2017; in revised form 11 January 2019; accepted 11 March 2019

This paper studies tax shifting of excise taxes on alcoholic and nonalcoholic beverages in Denmark. We use a unique data set collected by Statistics Denmark focusing on six episodes of tax changes: three tax cuts and three tax hikes. We find that excise taxes on beer and soda are overshifted but those on liquor are undershifted. We also find that the pass-through is inversely related to the size of the tax change and that there are asymmetric effects of tax changes on soda. Finally, the tax pass-through on beer and soda is an increasing function of the distance to the German border.

Keywords: tax incidence, excise tax, alcoholic beverages, nonalcoholic beverages

JEL classification: H 22, D 40

\section{Introduction}

It is well known that within a model with full competition, excise taxes (as well as ad valorem taxes) are fully passed on to prices, leading to a one-forone change in after-tax prices. ${ }^{1}$ The effect of a change in the excise tax on the after-tax price is less clear under imperfect competition, however. Excise taxes may in this case be undershifted or overshifted, depending on the elasticity of the demand function, on the relative slopes of the marginal cost and inverse demand functions, and on the number of firms and the possibility of entry. In single-product oligopoly models it can be shown that there is over-

* Bergman: University of Copenhagen, Øster Farimagsgade 5, building 26, DK-1353 Copenhagen, Denmark (Michael.Bergman@econ.ku.dk); Hansen: Copenhagen Business School, Porcelaenshaven 16A, 2000 Frederiksberg, Denmark (nlh.eco@cbs.dk). The viewpoints and conclusions stated are the responsibility of the individual contributors, and do not necessarily reflect the views of institutions we are affiliated to. We thank Bo William Hansen and Jakob Egholt Søgaard for excellent research assistance. We also thank two anonymous referees, Klaus Kristensen, Birgitte Sloth, Peter Birch Sørensen, and seminar participants at the University of Copenhagen and at the Danish Economic Society Conference in Kolding for helpful comments and suggestions. Financial support from EPRN is gratefully acknowledged

1 Fullerton and Metcalf (2002) survey both the theoretical advances and empirical studies of tax pass-through.

FinanzArchiv 75 (2019), 323-356 ISSN 0015-2218 doi: 10.1628/fa-2019-0010

(c) 2019 Mohr Siebeck 
shifting if demand is sufficiently convex; see Katz and Rosen (1985), Stern (1987), Besley (1989), and Delipalla and Keen (1992). The same conclusion also holds in an oligopoly model with heterogeneous goods, as shown by Anderson et al. (2001).

A potential problem is that overshifting requires a high degree of convexity, which is very often ruled out by standard assumptions underlying the oligopoly model. In particular, there is overshifting only when the demand curve is steeper than the marginal revenue curve. Formby et al. (1982) show that it is possible that the marginal revenue curve is positively sloped when market demand is convex. Furthermore, if individual demand is linear, it is easily shown that market demand will be convex. More recently, Hamilton (2008) has shown that in a model with multiproduct firms (retailers selling a wide variety of products), overshifting occurs except when demand is convex, a result opposite to the case when there is one homogeneous good or heterogeneous goods. The intuitive explanation is that an increase in the excise tax leads firms to reduce product variety, leading to less competition and therefore an increased excise tax pass-through. This effect is absent if demand is highly convex. Thus, excise taxes are undershifted in this case. From a theoretical viewpoint, one cannot therefore rule out the possibility that there is either under- or overshifting of excise taxes. It is therefore an empirical question whether excise taxes are undershifted, overshifted, or fully shifted to consumers.

The purpose of this paper is to study shifting of excise taxes on beverages (both alcoholic and nonalcoholic) at the micro level in Denmark. We focus on a total of six episodes of tax changes during the period 1997 to 2005. There are two episodes of tax changes on beer (a tax hike in 1997 and a tax cut in 2005), three episodes for soda (two tax hikes in 1998 and 2001, and one tax cut in 2003), and one episode of tax cuts on liquor (in 2003). Increases in excise taxes are in general used either to raise tax revenue or to discourage consumption of goods that have negative public-health effects. This last argument has seldom been used in the Danish debate motivating the changes in the excise taxes mentioned above. Instead, the underlying reason for tax hikes was to raise tax revenue, whereas the tax cuts were implemented in order to prevent further increases in cross-border shopping between Denmark and Germany, where alcohol taxes are much lower. We provide empirical evidence on how proximity to the German border affects the tax pass-through. Since our sample includes both tax hikes and tax cuts, we can examine the symmetry of tax pass-through.

Our study extends the literature in several ways. First, we focus on both the effect of excise taxes on homogeneous goods and the dispersion of these effects across outlets and across regions. Second, we examine the effects of both tax hikes and tax cuts on the same type of good. Third, we examine 
whether proximity to the German border affects the size of the excise tax pass-through. Fourth, a specific feature of the Danish retail market is that it is centralized, giving retailers greater bargaining power over the suppliers and allowing them to compete over customers.

Our paper is related to the empirical literature focusing on excise taxes, in particular excise tax changes on soda (Berardi et al. 2016; Falbe et al. 2015; Cawley and Frisvold, 2017; Grogger, 2017) and alcohol taxes (Young and Bielińska-Kwapisz 2002; Kenkel, 2005; Harding et al. 2010; Carbonnier, 2013; Conlon and Rao, 2016).

The paper is organized in the following way. In section 2 we provide an overview of the empirical literature. Section 3 discusses the institutional framework, including the specifics of the Danish retail market. Section 4 describes the data in detail. Section 5 contains our empirical analysis. Border effects are analyzed in section 6 , and finally section 7 concludes.

\section{Previous Literature}

There are an increasing number of empirical studies in the literature of the effects of excise-tax changes on prices. ${ }^{2}$ The main result from these studies is that tax incidence is heterogeneous across products: for some types of goods there is less than full shifting, whereas for other products the evidence suggests overshifting - see for example Poterba (1996) and Besley and Rosen (1999). More recent studies seem to confirm these findings. Carbonnier (2007) studies two VAT reforms in France, where the ad valorem tax was cut on car sales in 1987 and on housing repair services in 1999. He finds that tax shifting is higher on the housing repair service than on car sales, which is interpreted as evidence supporting the view that the former market is more competitive than the latter. Still, the empirical evidence suggests undershifting of ad valorem taxes during these two events. In a similar study, Zápal (2014) finds undershifting during the VAT reform in the Czech Republic in 2004 when the standard VAT tax rate was cut from $22 \%$ to $19 \%$ and the classification of commodities into standard and reduced VAT was changed. The data used in this study is very comprehensive and covers almost eight hundred commodities included in the CPI. The results suggest that small tax cuts (VAT declined from $22 \%$ to $19 \%$ ) have no effect on prices, whereas there is undershifting for larger tax increases (VAT increased from $5 \%$ to $19 \%$ ).

There is a growing literature on the effects of changes in excise taxes on alcoholic and nonalcoholic beverages. The conclusions from this literature on

2 Poterba (1996) reviews the early empirical studies going back to the 1930s, whereas Fullerton and Metcalf (2002) review both theory and more recent empirical results. 
the tax pass-through are also inconclusive. Some studies find undershifting, whereas other studies find overshifting or full shifting of excise taxes. This empirical literature is summarized in table 1. One of the first studies of tax incidence of excise taxes on alcoholic beverages in the United Kingdom - Baker and Brechling (1992) - found that excise taxes on beer and spirits were fully passed on to consumers, whereas for wine they found evidence suggesting overshifting. This study relied on aggregate retail price indexes. Besley and Rosen (1996) studied a limited number of goods, including Coca-Cola, and found that the excise tax on this product was overshifted to consumers. Young and Bielińska-Kwapisz (2002) examined whether beer taxes are good proxies for the price of alcohol and analyzed also how taxes on alcoholic beverages are passed through to consumers. Using U.S. data, they found that beer taxes are poor predictors of alcohol prices and that excise taxes are overshifted to consumers. Kenkel (2005) collected data on several brands of alcoholic beverages in Alaska and estimated the tax pass-through of the tax hike in October 2002. The main result is that excise taxes are overshifted (except for Miller beer): prices increase by 1.40-4.9 times the tax change. He also observes a high degree of heterogeneity both across brands and across different products. Common to these two last-mentioned studies is that they only examine the effects of tax hikes and they do not distinguish between types of stores or locations of stores, two aspects that may be of interest. Stehr (2007) relied on ACCRA data allowing him to empirically evaluate the impact of excise taxes, by extending the sample used by Young and Bielińska-Kwapisz (2002). The results still suggested overshifting of excise taxes on spirits, but tax changes on beer were fully shifted to consumers.

The implementation of the sugar-sweetened beverage (SSB) tax in Berkeley, California, in March 2015 is a natural experiment studied in a number of papers; see Falbe et al. (2015), Falbe et al. (2016), and Cawley and Frisvold (2017). Using different data sources, these papers all find that the SSB tax was undershifted to consumers. The size of the tax change stands out compared to changes in excise taxes in general: the $\$ 0.01 / \mathrm{oz}$ tax increase implied a change in the after-tax price of $10 \%$ on a can of soda costing \$2. SSB taxes have also been adopted in France and in Mexico. Berardi et al. (2016) study the effects of a new excise tax on drinks containing added sugar - a soda tax - introduced in France in January 2012. They find that taxes were fully shifted on to soda prices, whereas there was less than full pass-through on other beverages such as fruit drinks and flavored waters. Grogger (2017) studies the effects of the SSB tax that was adopted in 2014 in Mexico and finds evidence of overshifting.

There are few additional papers using a combination of time-series and cross-section analysis of the incidence of excise taxes. Harding et al. (2010) measure the excise tax incidence on cigarettes and beer, using Nielsen Homes- 
can data. ${ }^{3}$ They find almost full shifting of cigarette taxes and undershifting of beer taxes. In addition, they estimate border effects and find significantly negative effects on cigarette and beer prices if bordering states have lower taxes. Carbonnier (2013) compares the incidence of per-unit and ad valorem taxes on beer and aperitifs in France and finds that the effect of the former exceeds that of the latter. Shrestha and Markowitz (2016) use data on four different brands, study two tax hike events, and analyze whether the two major mergers in the beer industry have affected tax pass-through. They find that excise taxes are overshifted: a 10-cent increase in taxes on a six-pack of beer led to a 17-cent increase in after-tax prices during the period 2000-2014. Conlon and Rao (2016) estimate the effects of excise tax increases in Connecticut and in Illinois in July 2011. They find, using a unique data set from Nielsen Homescan, that tax increases on spirits were overshifted to consumers. However, they also note that a large share of stores did not adjust prices when the tax was increased.

Our unique data set allows us to study many different aspects that have been the focus in the previous literature and also some aspects not covered before. We study three different types of beverages and six excise tax changes, both tax cuts and tax hikes. The data set also allows us to examine spillovers from tax changes on one type of beverage to the other two types. Lastly, since aftertax prices on all three types of beverages are considerably lower in Germany, we consider the effects of proximity to Germany on the tax pass-through.

There are also other related studies focusing on specific products apart from beverages. Karp and Perloff (1989), estimating both the market structure and the tax incidence of ad valorem taxes on the Japanese television market, find that the tax is significantly overshifted to consumers on the color-television market, but they cannot reject full shifting on black-and-white television sets. They also find that the tax incidence varies with the size of the tax rate change. The tax incidence falls as the ad valorem tax rate increases. Delipalla and O'Donnel (2001), studying the European cigarette industry, find that the incidence of excise taxes always is greater than the incidence of ad valorem taxes. However, in countries relying on ad valorem taxation, such as in southern Europe, there is full shifting (and overshifting of excise taxes), whereas in northern Europe, where countries to a larger extent rely on excise or specific taxes, there is full shifting of excise taxes and undershifting of ad valorem taxes. DeCicca et al. (2013) find that the extent of tax shifting also depends on the extent to which consumers undertake search for volume discounts and on whether consumers engage in cross-state border trade. Doyle and Samphantharak (2008), studying the incidence of sales tax changes on gasoline prices

3 The published version of this paper excludes measures of the tax incidence of beer and focuses solely on cigarettes. 


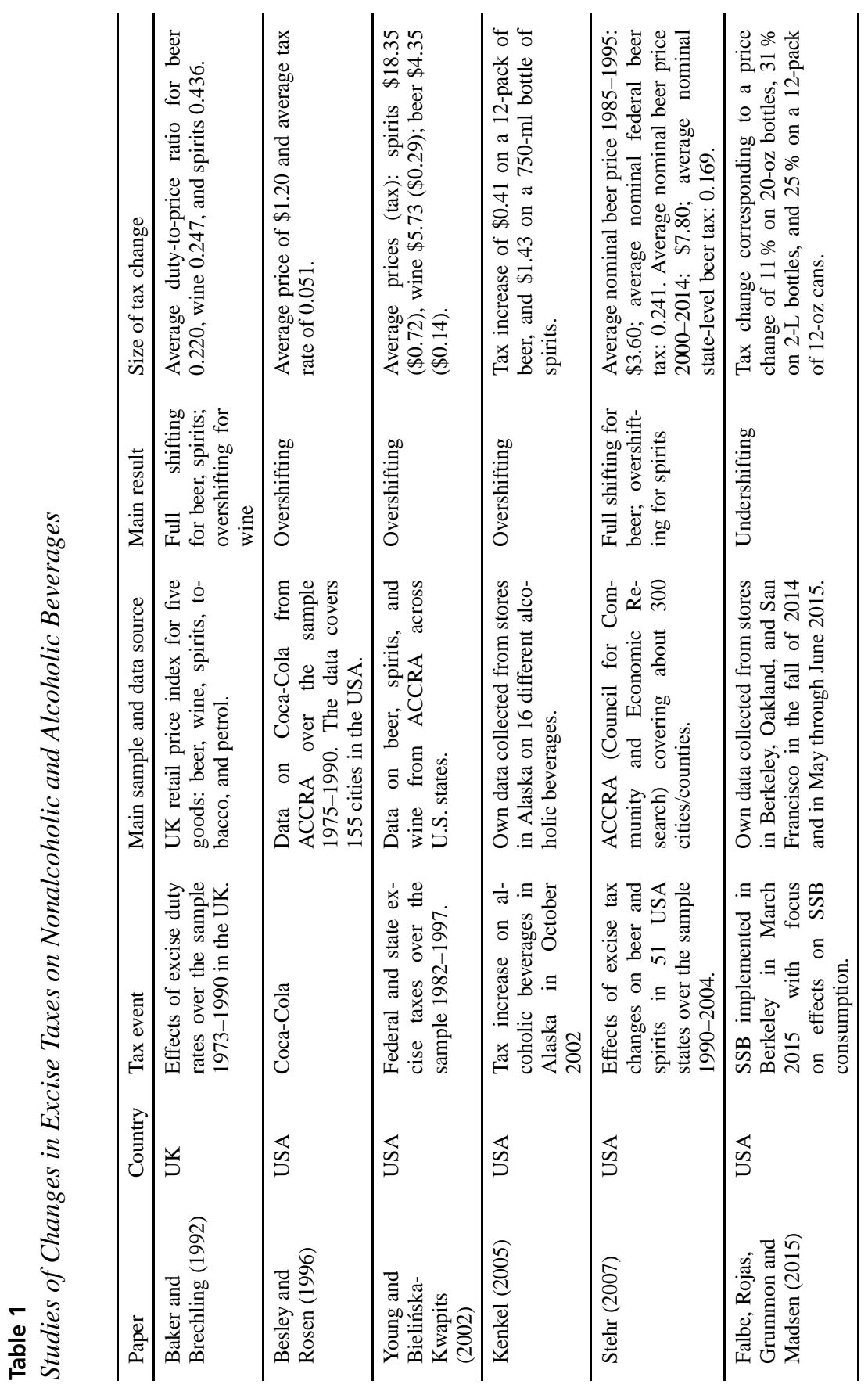




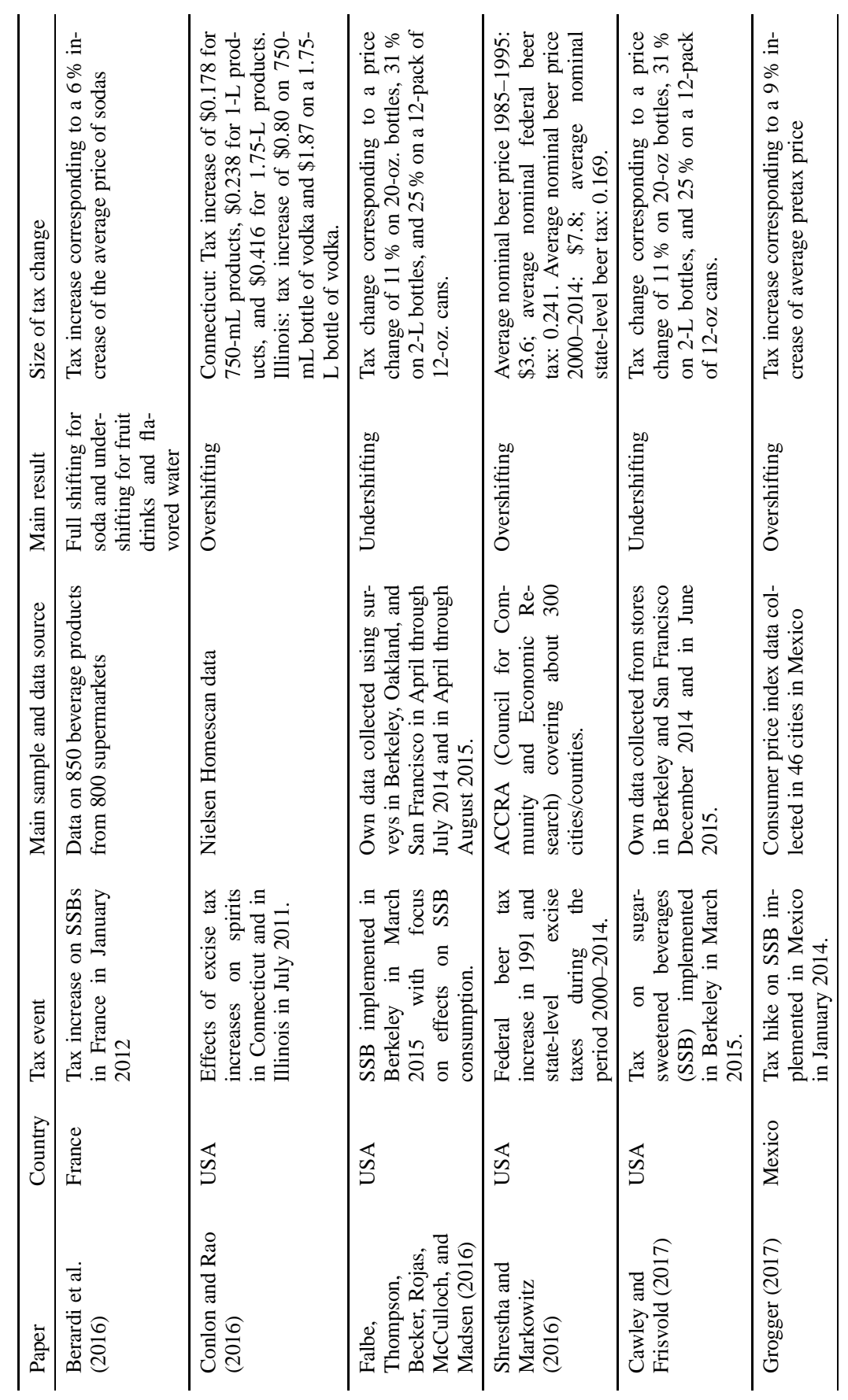


in the Midwest states, find undershifting of tax cuts and almost full shifting of tax hikes. In addition, they find that less than full shifting occurred in the least concentrated local areas when the sales tax was increased. Alm et al. (2009) study the gasoline market in the USA. Using data from all 50 U.S. states, they find that there is full shifting of gasoline taxes in urban states and undershifting in rural states, a result suggesting that in more competitive markets, taxes are fully shifted to consumers. Also studying gasoline taxes but distinguishing between federal and state taxes, Chouinard and Perloff (2004) find that a larger portion of state taxes are shifted to consumers in small states than in larger states. Comparing federal and state taxes, they find that there is undershifting of federal taxes and almost full shifting of state taxes.

In the next section, we first provide a brief overview of the Danish retail market and discuss the particularities of the excise tax changes on beverages, which we will analyze empirically.

\section{The Institutional Framework}

The Danish retail market is characterized by high concentration among both food retailers and suppliers, according to international standards; see Einarsson (2008) and the Danish Competition and Consumer Authority (2011). The three largest grocery chains account for around 90 percent of total sales in groceries. There is almost no competition from foreign chains; they account for around 10 percent of the market and are concentrated in the discount segment of the market. The high level of concentration in the retail sector enables grocery chains to exercise high market power over suppliers. In response to this, there are only a few suppliers; three major suppliers account for the majority of the market. Regarding alcoholic and nonalcoholic beverages, supply comes from only two suppliers. Even though the retail market is concentrated, the retailers have greater bargaining power over the suppliers and at the same time compete for customers. This is reflected by the extensive use of special offerings in order to attract customers. Many products or brands are considered as appeal products in their weekly brochures; see Danish Competition and Consumer Authority (2011). Another distinguishing feature of the Danish retail sector is that it is characterized by many small supermarkets situated close to each other and very few hypermarkets. This implies that productivity may be lower in general, since the market does not exploit economies of scale to the same extent as in other countries. One important reason why the market is structured in this way is the Planning Act, which regulates the size and location of stores. In addition, there is a Danish act that regulates opening hours. This act has been liberalized; from 2012 it has only regulated opening hours on holidays. 
The beverages we examine in this paper are all sold in general grocery stores and supermarkets as well as in specialized wine and liquor stores. There is no regulation prohibiting a retailer from offering special prices, and prices are set by the chain or by the individual store. Given that supermarkets are situated close to one another, it can be expected that they compete for customers. This is a specific feature of the Danish market structure that could potentially affect the tax pass-through. However, neither the retail market nor the supply sector can be regarded as fully competitive, and therefore we would expect to find both under- and overshifting of excise taxes as well as instances of full shifting. Since the market is segmented, the degree of competition may vary across time as well as across regions. Moreover, it may be that the excise tax pass-through varies across brands. We study six tax events, and implicitly we take into account changes in the degree of competition over time. Regional aspects and differences across brands will also be studied.

There are in total six episodes of changes in excise taxes during the period 1997-2005: two tax changes on beer, three on soda, and one on liquor. Table 2 provides examples of prices prior to the tax change and the implied change in the excise tax, all measured in DKK. The tax on beer was increased by 0.038 DKK or by 0.05 DKK per bottle, depending on alcohol per unit volume, on May 1, 1997 (see table 2 for specific tax changes for two different brands); on January 9, 2005 the tax was cut by 0.14 DKK or 0.18 DKK, respectively. ${ }^{4}$ For soda the excise tax was increased on January 1, 1998 from 0.80 DKK per liter to $1.00 \mathrm{DKK}$ per liter, corresponding to $0.13 \mathrm{DKK}$ on average per 50-cl bottle (the average price on soda was $6.88 \mathrm{DKK}$ at the time) and then further increased on January 1, 2001 to 1.65 DKK per liter (corresponding to 0.41 DKK per 50-cl bottle); on October 1, 2003 the excise tax was cut to 1.15 DKK per liter (corresponding to 0.31 DKK per 50 -cl bottle). This allows us to study the symmetry of effects of excise taxes on prices of soda. The tax on liquor was cut by 125 DKK per unit of 100-percent-pure alcohol on October 1, 2003. This corresponds to a decrease of the tax by 36.93 DKK on average for a bottle of liquor costing on average 139.25 DKK at the time. Table 2 provides two specific examples illustrating that the tax change is heterogeneous across different brands. In the following analysis we use the specific tax change on each type of beverage measured in DKK.

4 The excise tax on beer was also changed on October 1, 2004 so that the tax reflected the alcohol content. This change was neutral in that prices of beer were not affected. 
Table 2

Prices Prior to the Tax Change and the Change in the Excise Tax for Specific Beverages

\begin{tabular}{|c|c|c|c|c|c|}
\hline \multicolumn{6}{|c|}{ Beer } \\
\hline & \multicolumn{3}{|c|}{ Event: May 1997} & \multicolumn{2}{|c|}{ Event: January 2005} \\
\hline & \multicolumn{3}{|c|}{ Price Tax change } & \multicolumn{2}{|c|}{ Price Tax change } \\
\hline Tuborg Grøn & \multicolumn{3}{|c|}{$4.76 \quad 0.038$} & \multicolumn{2}{|c|}{$4.15-0.14$} \\
\hline Carlsberg Sort Guld 6 & \multicolumn{3}{|c|}{$6.81 \quad 0.05$} & \multicolumn{2}{|c|}{$6.90-0.18$} \\
\hline \multicolumn{6}{|c|}{ Soda } \\
\hline & \multicolumn{3}{|c|}{ Event: January 1998} & \multicolumn{2}{|c|}{ Event: January 2001} \\
\hline & \multicolumn{3}{|c|}{ Price Tax change } & \multicolumn{2}{|c|}{ Price Tax change } \\
\hline Coca-Cola $(50 \mathrm{cl})$ & \multicolumn{3}{|c|}{$\begin{array}{ll}7.57 & 0.13\end{array}$} & \multicolumn{2}{|c|}{$9.19 \quad 0.41$} \\
\hline Tuborg Squash $(50 \mathrm{cl})$ & \multicolumn{2}{|c|}{$\begin{array}{ll}7.52 & 0.13\end{array}$} & & \multicolumn{2}{|c|}{$9.54 \quad 0.41$} \\
\hline \multicolumn{3}{|c|}{ Soda } & \multicolumn{3}{|c|}{ Liquor } \\
\hline \multicolumn{3}{|c|}{ Event: October 2003} & \multicolumn{3}{|c|}{ Event: October 2003} \\
\hline & Price & Tax change & & Price & Tax change \\
\hline Coca-Cola $(33 \mathrm{cl})$ & 6.99 & -0.21 & Gammel Dansk & 93.12 & -41.56 \\
\hline Tuborg Squash $(50 \mathrm{cl})$ & 5.79 & -0.31 & Gin, Gordon Dry & 128.73 & -43.75 \\
\hline
\end{tabular}

Note: All prices and tax changes are measured in DKK.

\section{Data}

The data set contains micro data collected by Statistics Denmark in order to compute the Danish Consumer Price Index, covering the period January 1997 until December 2005 (108 months). The methodology used for compiling the data is provided in Statistics Denmark (2005). From this database we extract prices on beer, soda, and liquor. ${ }^{5}$

The raw database on the three types of beverages is made up of 114,615 monthly price records, or on average about 1061 observations per month. Prices are collected once each month (between the 7 th and the 15 th) from a selection of stores. Individual price quotes refer to a specific item sold in a particular retail outlet. The data set is subject to statistical confidentiality restrictions and does not reveal the name or location of a given outlet. For each item we observe the following information: the price of the item, the year and month the price was collected, the year and month the previous price

5 Hansen and Hansen (2007) have used the full set of data to study price-setting behavior in Denmark. 
was collected, the quantity content of the product, the brand name of the item, a numeric product code, a numeric product category code, the name of the product category, a numeric code for a given outlet chain, and a numeric outlet code. Together the four numeric codes relating to products and retail outlets allow us to identify and track each individual item, i.e., a specific item in a specific retail outlet. The product category code corresponds to the COICOP 5-digit code, whereas the data on individual prices from a retailer can be seen as a subdivision of the product category into the elementary product level (a 6-digit COICOP level) and further down to the specific brand. In addition to this data we have also information about the zip code of each specific store, allowing us to distinguish between stores located in different regions of Denmark. The data set is considered to be of a high quality and well suited for our purpose. Statistics Denmark has subjected the data to plausibility checks in order to detect possible errors such as extreme prices. However, not all price quotes are directly linked to an individual item sold in a particular outlet. In these cases prices are eliminated from the data set. There are no statistically imputed prices included in the data set.

Even though the data set is comprehensive, prices are not collected monthly from the same retail outlet during the full sample, and there are also some gaps in the data for specific outlets. Usually, there is a three-year window where prices on specific products are collected from the same outlet. The collected data on soda is an exception. For this type of beverage there are very short price spells. The number of price records for a specific product also changes over time. Very few prices are collected for some specific brands. For example, before January 2000 Danish Statistics collected 200 prices on the Danish liquor Old Danish (Gammel Dansk), but since October 2003 it has only collected 11 prices. For these reasons it is not possible to study the price behavior on the same product across different stores using the full sample. Since not all products are sold in the same retail outlet, we cannot analyze the effects of excise tax changes on one product on prices for other similar products. However, since our purpose is to study the excise tax pass-through during the six tax events, this is not crucial.

Another important characteristic of the data is that prices are inclusive of all types of sales, rebates, and promotions. Unlike liquor, which is hardly ever on sale, beer and soda are appeal products that grocery chains advertise with significant rebates in their weekly brochures to attract customers. Rebates of 20-40 percent for weekly periods and only a few weeks in between are not uncommon; see Danish Competition and Consumer Authority (2011). This can lead to a higher frequency of price adjustment for these products. Using a filter (filter B) suggested by Nakamura and Steinsson (2008), we construct reference price series for our data and then use these price trajectories instead of the raw data in our regression analysis. Comparing the raw data with the 
reference prices, we note that there are very few differences even for beer and soda. The reason for this is probably that rebates occur regularly and hence net out in our calculations. Usually there are only a very few price changes 6 months prior to the tax event. The same holds for the 12 months after each event. Therefore we only focus on estimates using the unfiltered data. ${ }^{6}$

The raw data set covering the six tax events includes 1605 price records of nonalcoholic and alcoholic beverages divided into 811 price records for beer, 639 for soda, and 155 for liquor. We have manually checked the data and corrected or excluded price records that clearly are misreported. We have used the following procedure. First, we check whether the previous price was collected in the previous month. If not, we exclude those price records. Second, we exclude price records where the content of the package had changed. Finally, we exclude price records for which there is no corresponding price record on the date of the tax event. For beer we find 23 price records where the lagged data was collected on another date than the previous month, 9 records where the content had changed and where there was no information about the new content, so that we could not compute the tax change in DKK, and 2 cases when the lagged price was missing. This implies that there are 777 available price records for beer. Using the same procedure for soda, we found 9 price records where the lagged price was not collected the month prior to the tax event, 23 where the content had changed, and 10 where the lagged price was missing. We therefore have a total of 597 price records for soda. Finally, for liquor we found 17 cases where the content had changed, so that there are 138 price records available.

Table 3 shows the total number of available observations for each type of beverage and for each tax event. In the first column we report the number of product groups at the 5-digit COICOP level, next follows the number of specific brands collected from a number of stores ("\# stores" in the table) belonging to a particular chain of stores, the number of chains ("\# chains") located in a specific region, and the number of zip codes ("\# zip") at the 2-digit level. Finally, we also report the maximum number of observations ("\# obs") of each type of beverage in the month where excise taxes was changed. As can be seen in the table, the total number of observations available on each tax event is different. For example, the data set contains 777 monthly price records for beer, of which 418 cover the first tax event in 1997 and 359 the second event in 2005. For soda there are 597 available price records divided over the three tax events, with roughly 200 records each. Finally, for liquor the number of available price records is 138 , all covering a tax cut.

6 We have run all our empirical tests below using the reference series and found that none of our conclusions were affected. 
Table 3

Summary of Data Available on Tax Events

\begin{tabular}{cccccccc}
\hline & & \# product groups & \# brands & \# stores & \# chains & \# zip & \# obs \\
\hline \multirow{2}{*}{ Beer } & $1997: 5$ & 2 & 25 & 63 & 17 & 43 & 418 \\
& $2005: 1$ & 3 & 35 & 61 & 16 & 30 & 359 \\
Soda & $1998: 1$ & 2 & 16 & 62 & 17 & 42 & 208 \\
& $2001: 1$ & 2 & 13 & 57 & 16 & 30 & 201 \\
& $2003: 10$ & 2 & 26 & 62 & 16 & 28 & 188 \\
Liquor & $2003: 10$ & 6 & 24 & 22 & 7 & 14 & 138 \\
\hline
\end{tabular}

Note: \# product groups refers to the number of COICOP-5 product groups, \# brands is the the number of specific brands, \# stores is the number of distinct stores, \# chains is the number of chains of stores identified by Statistics Denmark, and \# zip refers to the two-digit zip codes.

\section{Figure 1}

\section{Price Trajectories}
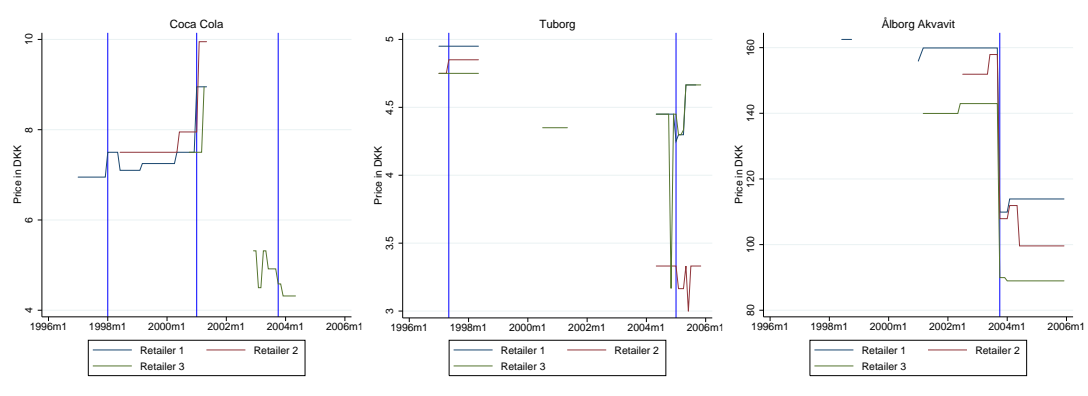

From the information in the data set we construct individual price trajectories, i.e., sequences of price quotes for a specific item sold in a specific outlet. In most cases the trajectories are considerably shorter than 108 months, as explained above. In figure 1 we show some examples of price spells. These are chosen to illustrate and represent typical price trajectories in the data. We show prices of three different products, Coca-Cola, Tuborg beer, and Ålborg Taffel Akvavit, from three different retailers. As can be seen in the graph, prices do not change very often; there are long periods over which they remain constant. The vertical lines in the graphs indicate when there was a change in the excise tax on that specific type of beverage. This allows us to study how prices on these particular goods were affected before, during, and after the tax event.

First, judging from these graphs (and also as confirmed to a large extent by our empirical analysis below), it seems as if retailers do not increase their price just prior to the tax change. During the month when the new tax was imposed, retailers also changed their after-tax prices. Looking at the first graph, we 
note that one retailer decided to adjust prices in response to the excise tax during the first event. Two retailers immediately adjusted prices during the second event, whereas one retailer waited two months before changing the price. Also interesting to note is that the price of Coca-Cola is very similar across the retailers. The jump in the price level between the period covering the first two events and the last tax event does not represent a general price fall, but the fact that prices were not collected for the same content. There are a number of such changes in the sample, as mentioned above.

The second graph shows prices of Tuborg beer. For this type of beverage we note that there are very few price changes during the first tax event. Two retailers kept prices constant, whereas one retailer increased the price when the tax was increased. Around the second tax event we note a case of a sale on Tuborg: one retailer decided to cut the price temporarily two months before the tax cut and then decided to let the price return to the previous level. The following month when the tax was cut, the same retailer decided to decrease the price again. A similar case of sales is evident for another retailer (the red line in the graph). The price was temporarily cut a few months after the tax event and then returned to the pre-tax-change level.

We find quite different behavior of liquor prices, as illustrated in the third graph, showing the price of Ålborg Taffel Akvavit in three different stores. In general the price was cut immediately after the tax cut and then remained fairly constant over time. Judging from these graphs, the frequency of price changes for both beer and soda seems to exceed the frequency of price changes on liquor. Furthermore, from these graphs (and inspection of price trajectories for all other brands and retailers) we conclude that pricing behavior is heterogeneous and that the average length of a price spell varies significantly between products and across retailers.

To illustrate how the frequency of price changes vary over time we show, in figure 2, the frequency of price changes across the three types of beverages for the full sample. ${ }^{7}$ We have also added vertical lines indicating the dates of the five excise tax changes: black bars indicate excise tax changes on beer, blue bars indicate excise tax changes on soda, and the black bar indicates an excise tax change on both soda and liquor. There are a couple of interesting features to note. First, there is no clear indication that there is an anticipation effect, i.e., that stores decide to change the price prior to the excise tax change. Second, and in accordance with previous results, most stores change their after-tax prices when the excise tax changes. The frequency of price changes falls substantially the month after the tax change. Third, there is a clear heterogeneity across types of beverages. The frequency of price changes in connection with

7 We have used the information given in the data to compute monthly price changes, taking into account any change in the content of the packages. No other filtering has been used. 


\section{Figure 2}

Frequency of Price Changes
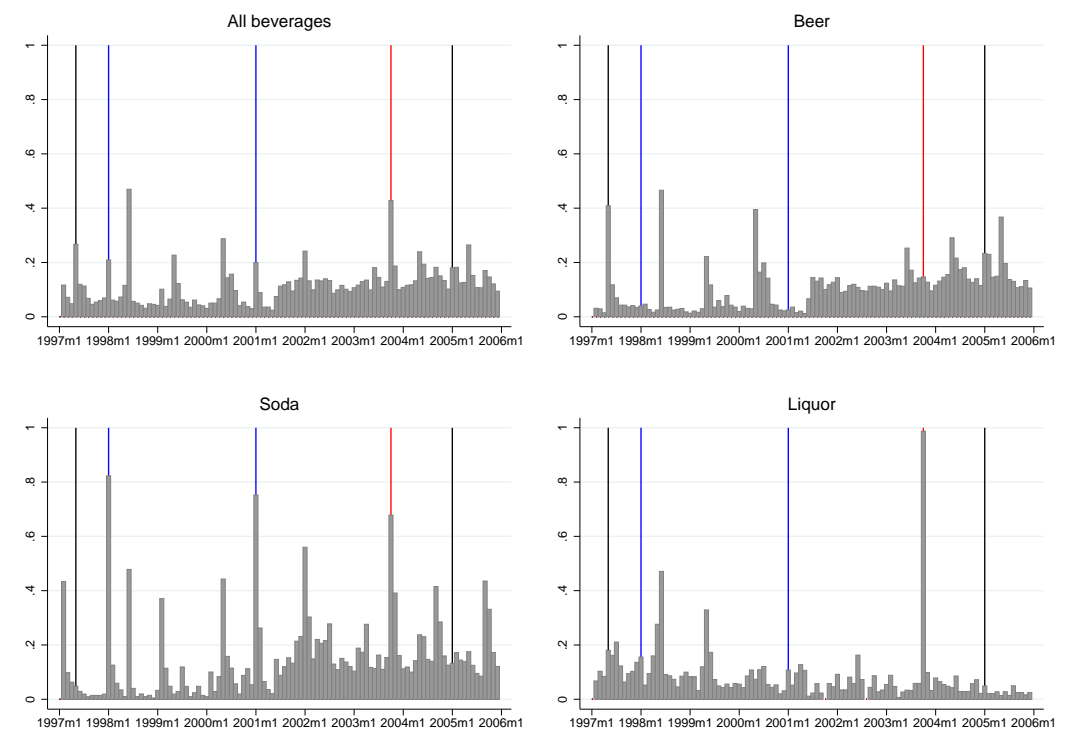

Note: Black bars indicate excise tax changes on beer, blue bars indicate excise tax changes on soda, and the red bar indicates an excise tax change on both soda and liquor.

tax changes is highest for soda and liquor, and substantially lower for beer. There is also an apparent seasonality in price changes: stores tend to adjust prices in June each year. This pattern is most evident for soda. Fourth, the frequencies shown in the graph do not indicate that retailers adjust prices on beverages that are not affected when there is a tax change on other beverages.

Using the frequencies of price adjustments shown in figure 2, we ran regressions with seasonal dummies for each type of beverage where we exclude the tax events. ${ }^{8}$ We find that prices on beer are typically adjusted in June each year, but also in January and May to a large extent. For soda and liquor we find that prices are adjusted in January. Another question is whether, say, prices of soda are adjusted at the time of tax changes on beer and/or on liquor. A casual look at the figure suggests that this is not the case. Unfortunately, it is not possible to systematically examine this question using the data available, since prices of the three types of beverages are not collected from the same store over the full sample. Instead, we make use of the estimated frequency of

8 These results are not shown here, for brevity, but are available from the authors upon request. 
Table 4

Change in Frequency of Price Changes When Taxes Change

\begin{tabular}{lccc}
\hline & Beer & Soda & Liquor \\
\hline Tax increase on beer May 1997 & $0.307 * * *$ & $-0.072 * * *$ & $0.106^{* * *}$ \\
Tax increase on soda January 1998 & $(0.008)$ & $(0.013)$ & $(0.007)$ \\
& $-0.056^{* * *}$ & $0.702 * * *$ & $0.083^{* * *}$ \\
Tax increase on soda January 2001 & $(0.008)$ & $(0.013)$ & $(0.007)$ \\
& $-0.078^{* * *}$ & $-0.110^{* * *}$ & $-0.017 * *$ \\
Tax cut on soda and Liquor October 2003 & $(0.008)$ & $(0.013)$ & $(0.007)$ \\
& $(0.008 * * *$ & $0.504 * * *$ & $0.914 * * *$ \\
Tax cut on beer January 2005 & $0.126 * * *$ & $-0.034 * * *$ & $-0.029 * * *$ \\
Constant & $(0.008)$ & $(0.013)$ & $(0.007)$ \\
& $0.098^{* * *}$ & $0.120 * * *$ & $0.071 * * *$ \\
\hline Adj. $R^{2}$ & $(0.008)$ & $(0.013)$ & $(0.007)$ \\
Obs. & 0.121 & 0.291 & 0.651 \\
\hline
\end{tabular}

Note: Tax changes are represented by dummy variables equal to one in the month of a tax change and zero otherwise. Robust standard errors are shown within parentheses below each estimate.

price changes, testing whether the frequency of price changes on (for example) beer significantly increases when there are tax changes on soda or liquor. The results are shown in table 4.

Several interesting features appear in this table. First, as expected, we find strong positive and significant effects of own tax changes. For example, the tax increase on beer in 1997 increased the frequency of price changes by $31 \%$, the tax cut on soda and liquor in 2003 increased the frequency of price changes by $50 \%$ and $91 \%$, respectively, and the tax increase on soda in 1998 increased the frequency of price changes by $70 \%$. The tax cut on beer in 2005 had only small effects, and the tax increase on soda in 2001 likewise had only small effects (positive on beer but negative on soda). Considering the cross effects, we find that the frequencies of price changes for other types of beverages are either negative, implying a fall in the frequency, or very slightly positive. One should also keep in mind that prices of soda and liquor are adjusted in January, coinciding with most of the tax changes. The tax change in October 2003, when taxes were cut on both soda and liquor, is an interesting case. As can be seen in table 4 , there is a strong and significant increase in the frequency of price changes for these two products, but there is also a minor increase in price adjustments on beer ( $4.4 \%$ increase). Our conclusion from these results is that there are only minor or even negative cross effects of tax changes on the frequency of price changes. Therefore, it is likely that the fact that we cannot 
follow price changes on all three types of beverages in a particular store over time will not severely bias our results below.

Figure 2 suggests that the frequency of price changes tends to increase after a tax event. To shed further light on this possibility we compute the absolute value of the average pretax (over the previous three months) and the absolute value of the average posttax price change (three months after the tax event and including the month when the tax was adjusted) and divide by the average price. Figure 3 shows scatterplots of these price changes. We also include a 45degree line in the graphs. In the upper left-hand graph we show a scatterplot including all three types of beverages. It is not very clear whether the price changes after tax events exceed those before the tax event. There are many cases where prices do not change after the tax event and there are a number of cases where the tax change before the tax event exceeds the average price change after the event. Looking more closely, we find that the average price change after the tax event exceeds the average price change before the event in 68 percent of the cases. The other three graphs show scatterplots for each type of beverage. There are large differences. For liquor (see the graph on the lower right-hand side) all except one price change after the tax hike exceeds the before-event average price change. For soda and beer the shares of cases where the after-event price change exceeds the before-event price change are 51 percent and 84 percent, respectively. These differences will likely affect the tax pass-through, and we would expect to find full shifting or overshifting for liquor and maybe also for soda.

Table 5 shows the frequency of price changes, the size of price changes and its standard deviation, the fraction of price increases, and the implied duration computed using the formula $-1 / \ln (1-F)$, where $F$ is the fraction of retailers changing the price each month. These statistics are computed using the full sample and all available price trajectories where we have at least 12 months of available observations. ${ }^{9}$ In addition to showing aggregated results for each type of beverage, we also report results for a few different product groups (COICOP 6-digit level). What is most striking about the statistics in table 5 is that prices of beverages are held constant over longer periods. Looking at the last column, we find that the average price spells are in the range of 8 to 16 months at the aggregate level. Each month the majority of retailers refrain from adjusting the price. As expected, prices on beer and soda are adjusted more frequently than prices on liquor, a finding also evident in figure 1. Looking at the actual size of the price change in percent reported in column 4, we see that the percentage change is lowest for liquor and highest for beer in tax class I (Tuborg for example).

9 As in the data shown in figure 2, we have only excluded price trajectories where the content of the package has changed. 
Figure 3

Average Price Changes Before and After-Tax Events
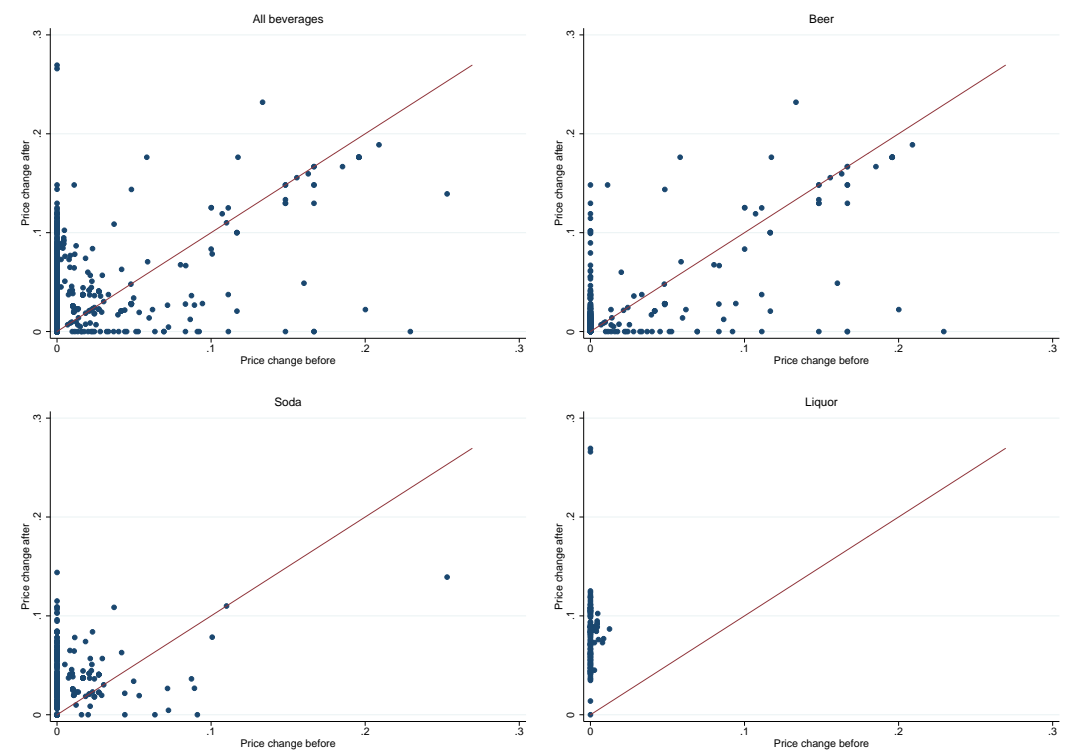

Note: The graphs show the absolute value of the average pretax (over the previous three months) price change and the absolute value of the average posttax price change (three months after the tax event and including the month when the tax was adjusted), divided by the average price.

\section{Empirical Analysis}

Following the standard practice in the empirical literature, we estimate the tax pass-through of excise taxes using the panel-data regression model

$$
\Delta p_{i, j, t}=\sum_{k=0}^{4} \beta_{k} \Delta \tau_{i, t-k}+\alpha_{i}+\alpha_{t}+\sum_{k=1}^{N} \gamma_{k} X_{t}+\varepsilon_{i, t},
$$

where $\Delta p_{i, j, t}$ is the change in the after-tax price of beverage $i$ in store $j$ between $t$ and $t-1$ measured in DKK, $\Delta \tau_{i, t}$ is the change in the excise tax measured in DKK for beverage $i$ at time $t, X_{t}$ is a vector of $N$ control variables (to be defined below) that are constant across stores but time-varying, $\alpha_{i}$ is fixed effects, $\alpha_{t}$ is time effects, and $\varepsilon_{i, t}$ is the beverage-specific residual. It is common in the literature studying tax pass-through to include cost and demand variables (Baker and Brechling, 1992; Besley and Rosen, 1996; Delipalla and O'Donnel, 2001; Carbonnier, 2007; Alm et al. 2009). We use the following control variables to take into account costs facing retailers: the 
Table 5

Relationship Between Absolute Change in Prices and Frequency of Price Changes for Beer, Liquor, and Soda Conditional on at Least 1 Year of Available Data

\begin{tabular}{lccccccc}
\hline & Products & Obs. & $\begin{array}{c}\text { Frequency } \\
\text { price changes }\end{array}$ & $\begin{array}{c}\text { Size of } \\
\text { price changes }\end{array}$ & St. dev. & $\begin{array}{c}\text { Price } \\
\text { increases }\end{array}$ & Duration \\
& & & \multicolumn{7}{c}{ Beer } \\
\hline All beer & 122 & 58369 & 0.061 & 0.352 & 2.318 & 0.419 & 15.9 \\
Beer tax class I & 48 & 19464 & 0.090 & 0.627 & 3.224 & 0.680 & 10.6 \\
Beer tax class I, canned & 16 & 1733 & 0.062 & 0.114 & 0.165 & 0.454 & 15.6 \\
Beer tax class II & 27 & 18914 & 0.052 & 0.053 & 0.074 & 0.670 & 18.7 \\
Low and nonalcoholic beer & 31 & 18258 & 0.032 & 0.077 & 0.150 & 0.799 & 30.7 \\
\hline & & & & Soda & & & \\
\hline All soda & 67 & 21410 & 0.111 & 0.155 & 0.267 & 0.531 & 8.5 \\
Soda & 20 & 5435 & 0.084 & 0.078 & 0.076 & 0.904 & 11.4 \\
Coca-Cola & 40 & 14831 & 0.119 & 0.178 & 0.299 & 0.663 & 7.9 \\
Soda, canned & 7 & 1144 & 0.047 & 0.081 & 0.101 & 0.296 & 20.8 \\
\hline & & & & Liquor & & & \\
\hline All spirits and liqueurs & 79 & 30081 & 0.072 & 0.046 & 0.085 & 0.531 & 13.4 \\
Aquavit and bitter & 2 & 9470 & 0.078 & 0.036 & 0.066 & 0.724 & 12.3 \\
Old Danish & 1 & 10683 & 0.084 & 0.030 & 0.050 & 0.731 & 11.4 \\
Gin, vodka, etc. & 22 & 2324 & 0.059 & 0.098 & 0.162 & 0.630 & 16.4 \\
Liqueurs & 18 & 3528 & 0.046 & 0.084 & 0.133 & 0.590 & 21.2 \\
Whiskey & 16 & 1856 & 0.051 & 0.094 & 0.135 & 0.553 & 19.1 \\
Brandy & 20 & 2220 & 0.041 & 0.088 & 0.124 & 0.500 & 23.9 \\
\hline
\end{tabular}

Note: The table reports the frequency of price changes per month for each beverage, the average size of price changes, the standard deviation of the size, and the implied duration computed using the formula $-1 / \ln (1-F)$, where $F$ is the frequency of price changes in column 4 .

change (Labcost) and the squared change (Labcost $\left.{ }^{2}\right)$ in unit labor costs, the rent price index (Rent), and the energy price index (Energy). ${ }^{10}$ These variables are time-varying but constant across stores. To capture the developments in the general price level we add the change (CPI) and squared change in the consumer price index $\left(\mathrm{CPI}^{2}\right) .{ }^{11}$ Since we have access to the zip codes of each store in our sample, we also add disposable income as a proxy for aggregate demand (Baker and Breichling, 1992). However, Statistics Denmark does not publish data on disposable income for all zip codes, only for major towns or

10 Initially we also added the squared values of the latter two prices, but found that they were both insignificant. Therefore we have excluded these squared terms in our base specification.

11 Ideally we should filter out the effects of prices of alcoholic and nonalcoholic beverages from the overall CPI index. However, the weights associated with these products are very small. Even for large changes in prices of liquor (as was the case in October 2003, when the excise tax was cut, leading to a fall in the price index on these beverages of about 30 percent), there was no similar jump in the overall CPI. It is likely that price changes on beverages do not exert an important influence on the overall CPI. 
regions. In addition, the data is annual, implying that the inclusion of disposable income as an additional control variable amounts to adding another fixed effect. We have, nevertheless, matched the available income data with zip codes in our sample. Unfortunately, the number of available observations falls substantially. Therefore, we focus on results where we exclude disposable income, and then we add this control as a robustness test and present detailed results in the Appendix.

Given our definition of the variables in our regression model, we find that the excise tax pass-through is given by $\frac{\Delta p}{\Delta \tau}=\sum_{k=0}^{4} \beta_{k}$. The reason why we allow for lagged effects is that it may be that a retailer decides to adjust the price in the following months after the actual implementation of the new excise tax. ${ }^{12}$ In our empirical specification we allow for up to four months delayed effect on the after-tax prices. This assumption is consistent with the trajectories shown in figure 1, where some retailers decided to adjust the price just a few months after the tax event. We will estimate the regression model in equation (1) for all beverages and tax events as well as for each type of beverage, to allow us to contrast tax pass-through across beverages. As there are both tax hikes and tax cuts for soda and beer, we also test for asymmetric responses in the data. As mentioned above, there are gaps in the data, implying that our panel is unbalanced. All our estimations take this into account.

\subsection{Estimating Excise Tax Pass-through for Types of Beverages}

Table 6 reports the baseline regression results. ${ }^{13}$ The first column reports the results of using all three types of beverages, and the following columns report the results for each different type of beverage. We use, as was explained above, fixed-effects estimators, and we also add time effects. ${ }^{14}$ As controls we use changes in rent, energy, and unit labor cost as proxies for costs, and we allow for nonlinear effects from labor costs. In addition we add changes in the CPI (and allow for nonlinear effects) to allow for general changes in prices. Below we will also present results where disposable income is included as a proxy for aggregate demand.

The first row reports the contemporaneous tax pass-through, with robust and clustered standard errors within parentheses below the point estimate and with the $p$-value of tests for full pass-through, i.e., that the tax pass-through

12 We have also experimented with both fewer and additional lags, but the main results are not affected.

13 We have estimated the models using pooled OLS, adding fixed effects at the brand level and at the type of beverage. The results reported are robust to these additional fixed effects.

14 We have used Hausman specification tests to test for the appropriateness of random effects against fixed effects. The results show that we always can reject the null that the randomeffects model is appropriate. 
Table 6

Estimates of Excise Tax Pass-through for Each Type of Beverage

\begin{tabular}{lcccc}
\hline & All beverages & Beer & Soda & Liquor \\
\hline$\beta_{0}$ & $1.029 * * *$ & $6.388^{* * *}$ & $1.734^{* * *}$ & $0.781^{* * *}$ \\
& $(0.014)$ & $(1.091)$ & $(0.106)$ & $(0.076)$ \\
& {$[0.044]$} & {$[0.000]$} & {$[0.000]$} & {$[0.005]$} \\
$\sum_{k=0}^{4} \beta_{k}$ & $1.027 * * *$ & $8.512^{* * *}$ & $2.398^{* * *}$ & $0.717 * * *$ \\
& $(0.014)$ & $(1.671)$ & $(0.215)$ & $(0.070)$ \\
& {$[0.051]$} & {$[0.000]$} & {$[0.000]$} & {$[0.000]$} \\
\hline Rent & $-0.021 *$ & $-0.504 * * *$ & 0.012 & $-3.761 *$ \\
& $(0.011)$ & $(0.119)$ & $(0.025)$ & $(2.067)$ \\
CPI & $-0.061 * * *$ & $-0.277 * * *$ & $-0.114 * * *$ & -0.127 \\
& $(0.021)$ & $(0.072)$ & $(0.036)$ & $(1.140)$ \\
CPI ${ }^{2}$ & 0.090 & $0.300^{* * *}$ & $0.228 * * *$ & 1.049 \\
& $(0.074)$ & $(0.092)$ & $(0.081)$ & $(2.255)$ \\
Energy & 0.020 & -0.015 & $-0.026 * * *$ & 0.169 \\
& $(0.014)$ & $(0.013)$ & $(0.010)$ & $(0.164)$ \\
Labcost & $0.038^{* * *}$ & $0.076^{* * *}$ & 0.002 & $0.457 * *$ \\
& $(0.007)$ & $(0.019)$ & $(0.008)$ & $(0.221)$ \\
Labcost ${ }^{2}$ & 0.010 & $0.215^{* * *}$ & $-0.037 *$ & -0.330 \\
& $(0.007)$ & $(0.041)$ & $(0.021)$ & $(0.285)$ \\
\hline Adj. $R^{2}$ & 0.920 & 0.019 & 0.331 & 0.930 \\
\# Groups & 1508 & 775 & 595 & 138 \\
\# Obs & 15384 & 8778 & 4699 & 1907 \\
\hline
\end{tabular}

Note: The table reports fixed-effects estimates of equation (1) including time effects. Robust and clustered (on goods) standard errors are reported within parentheses below each point estimate. $p$-values of tests of full tax pass-through (that the contemporaneous or total tax pass-through is equal to unity) are reported within brackets.

is equal to one. Next, we report the sum of the contemporaneous and lagged (allowing for up to four lags) tax pass-through including standard errors and the $p$-values of a test of full pass-through within brackets.

We find in the first column that the contemporaneous pass-through is very close to one. The same holds when adding up all lagged and contemporaneous effects. However, we reject the null hypothesis that the pass-through is full at the $5 \%$ level. The precision of the estimates, judging from the standard error, is very high. Turning to the individual beverages, we reject full tax pass-through in all cases, and we find that the total effect of tax changes exceeds the contemporaneous effect for beer and soda. In this respect, liquor behaves differently: the contemporaneous effect exceeds the total effect. Another interesting difference is that we find overshooting for beer and soda but undershooting for liquor. In some cases (all beverages and liquor) we find that the contemporaneous tax incidence exceeds the lagged effect. This is due to 
negative lagged responses of price changes to tax changes. Figure 3 above suggested that prices of beer and of soda changed prior to the tax events. To shed further light on the question of anticipation, we run regressions testing explicitly if there are significant price changes three months prior to the tax change. We estimate fixed-effects panel-data models identical to those reported in table 6 for each type of beverage. Due to multicollinearity, we can only allow for three leads and three lags in addition to a contemporaneous effect of tax changes on prices. ${ }^{15}$ The results suggest that we can reject anticipation effects (testing whether the lead effects are significantly different from zero) for soda ( $p$-value equal to 0.21 ) and for liquor ( $p$-value equal to 0.60$)$. For beer we find an anticipation effect for tax cuts ( $p$-value equal to 0.03 ) but not for tax hikes ( $p$-value equal to 0.16 ). According to these results, anticipation effects do not appear important for soda and liquor.

The control variables are often significant. CPI, energy prices, and labor cost all exert a positive effect on beverage prices, as expected. Rent is significant and negative in three regressions but is insignificant when estimating the model using soda prices. The last three rows of the table reports the adjusted $R^{2}$, number of groups (beverage price records in a specific store), and number of observations. Two regressions stand out with respect to $R^{2}$ : those when using all data, and those when using only data on liquor. By contrast, we find that the regression using beer prices is not well specified; the $R^{2}$ is almost zero. This is surprising, since several of the control variables as well as the tax change significantly affect beer prices. However, when looking at the frequencies of price changes on beer, we find that $53 \%$ of the retailers adjusted beer prices in connection with the first tax change in May 1997 (3\% of the stores decreased prices, whereas $50 \%$ increased prices). For the tax cut in 2005 we find that only $16 \%$ of the stores cut the price (16\% of the stores increased prices, and $68 \%$ did not adjust to the tax change). As a consequence, the explanatory power of tax changes (and controls) is likely to be small when estimating the model for beer, compared to the regressions for soda and liquor, where a larger number of prices were adjusted in response to the tax changes. The regression for soda seems reasonably well specified; the controls explain about $33 \%$ of soda prices.

The inclusion of disposable income does not affect our main conclusions for soda and liquor; see table 9 in the appendix. However, the total tax passthrough using the full sample turns out to be negative, instead of positive as in our base results, and the estimates for beer change substantially. One reason for these changes is that the estimates when including disposable income are based on fewer observations and fewer beverages. In our full sample we have 1508 different price records and 15,384 observations in total, whereas

15 These results are not reported, for brevity, but are available upon request from the authors. 
when including disposable income we only have 988 beverages and 7696 observations. The number of observations available for beer is 3868 ( 355 price records) when including disposable income, but 8778 (775 price records) in our base case. A closer look at the contemporaneous tax pass-through reveals a much higher standard deviation for beer (3.1) than for soda (1.8) and for liquor (0.35). It is likely that this explains why the estimated tax pass-through for beer (and therefore for all beverages) changes substantially on limiting the sample.

The data available also allows us to investigate whether there are differences in how different types of stores (or chains of stores) respond to the tax changes. We estimate panel-data regressions as above, using the full set of data, and interact the tax changes with a dummy variable taking on the value 1 to 18 representing each type of stores. Note that Statistics Denmark does not collect data on all three types of beverages from all of these 18 chains. Prices of beer and soda are collected from 17 of these chains, whereas prices of liquor are only collected from seven of them (including one where there are no collected prices of beer or soda). Two different regressions are estimated. In the first, we estimate the average tax pass-through for each chain of stores, using only data on beer and soda. In the second regression, we estimate the model using the full sample of beverages and distinguish between the three types, so that we obtain an estimate of the average tax pass-through for each type of beverage in each of the at most 17 different chains of stores. As above, we also include all control variables added in the regressions reported in table 6. The resulting estimates of the tax pass-through are shown in figure 4. In the graph on the LHS we show the average tax pass-through on beer and soda for each chain of stores where data is available, including the $95 \%$ confidence bands. In the RHS graph we distinguish between the all three types of beverages for each chain of stores. A red horizontal line showing complete pass-through is added in both graphs.

From the graph on the LHS it is clear that the responses are heterogeneous: the tax pass-through depends on the type of store the data is collected from. The pass-through either is complete (not significantly different from zero) or exceeds complete pass-through. Looking at the confidence bands, we find 16 cases where the bands overlap, indicating a rejection of the null hypothesis that the pass-through is identical. Indeed, a formal test reveals that we can reject the null hypothesis that the tax pass-through is equal across all chains of stores. In the RHS graph we show the estimated tax pass-through on all three types of beverages for these 18 chains of stores. This figure also suggests a high degree of heterogeneity, but there is no apparent systematic response. Chains of stores where the tax pass-through on one type of beverage is sizable do not respond in a similar way to tax changes on other beverages. For example, in chain 6 the tax pass-through on beer is very large, whereas the pass-through 


\section{Figure 4}

Estimated Tax Pass-through for Different Chains of Stores
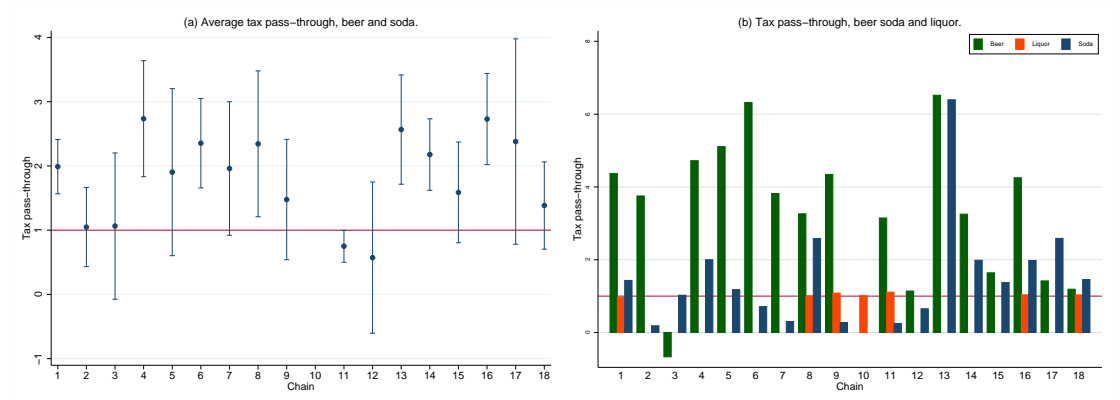

Note: The LHS graph reports the results from fixed-effects estimates of equation (1) using only data on beer and soda, where we have added dummy variables representing different chains of stores. The RHS graph shows fixed-effects estimates of equation (1) for each type of beverage separately, where we have added dummy variables representing different chains of stores.

on soda is below one. There are only two chains where the pass-through on soda exceeds the pass-through on beer (chains 17 and 18). The data available to us does not, unfortunately, allow us to investigate the reasons for these differences. We have no further information on any distinguishing features of the chains apart from the zip code. ${ }^{16}$ Below we will use this information to test whether the distance to the German border can explain the size of the tax pass-through. However, in the next section we first turn to the question of asymmetric responses to tax hikes and tax cuts.

\subsection{Testing for Asymmetric Excise Tax Pass-through}

In this subsection we estimate and contrast the tax pass-through of tax cuts and tax hikes. We define a dummy variable $\left(D_{i t}\right)$ equal to one if there is a tax increase on beverage $i$ and zero otherwise, and we extend equation (1) in the

16 Even though we have access to a rich aggregated data set, it is not possible to disaggregate down to individual stores in a meaningful way. The number of stores within each chain ranges between 110 for chain 1 and 5 for chain 4 . Looking more closely at chain 1 , we find two different stores where prices are collected on both soda and liquor (four brands in total) and no store where there are price records on both beer and liquor. The same holds for stores where we have price records on both beer and soda; at most we find four price records from these stores. The information that can be extracted from these price records is limited, and therefore we refrain from looking at the data at the store level. 
following way:

$$
\Delta p_{i, j, t}=\sum_{k=0}^{4} \beta_{k} \Delta \tau_{i, t-k}+\sum_{k=0}^{4} \gamma_{k} D_{t} \Delta \tau_{i, t-k}+\alpha_{i}+\alpha_{t}+\sum_{k=1}^{N} \gamma_{k} X_{t}+\varepsilon_{i, t}
$$

where all variables are defined as in our baseline model. As above, we also add individual unobserved fixed and time effects.

Table 7 (analogous to table 6) reports the results. In the same way as in table 6 , we provide the estimated contemporaneous effect as well as the total effect. We also provide a formal test of whether the tax pass-through is equal during tax cuts and tax hikes; the $p$-value is reported within brackets. Consider first our estimates of the excise tax pass-through on all beverages, reported in the first column. The contemporaneous pass-through of a tax cut is estimated to be 1.026 , which is significantly different from one. We find that the passthrough during tax hikes is substantially higher, 2.4 , also significantly different from one. Adding the lagged effects of tax changes, we cannot reject the null hypothesis that the tax pass-through is equal to one for tax cuts; see the $p$ value reported in brackets. By contrast, we find significant overshifting for tax hikes; the total effect of a tax hike is three times as large as for tax cuts. This suggests an overall asymmetry in the responses to tax hikes and tax cuts, with full shifting of tax cuts but overshifting of tax hikes.

Comparing the results for beer and soda (reported in the second and third columns of table 7), it seems that beer and soda prices respond differently. For beer we find significant overshifting for both tax cuts and tax hikes, but three times as large a pass-through for tax hikes; but for soda we find insignificant response of prices to a tax cut and overshifting of tax hikes. Again we find that the model does a poor job explaining beer prices; $R^{2}$ is very small. However, taking into account the magnitude of the tax changes on beer, which is $0.8 \%$ for tax hikes versus $3 \%$ for tax cuts, we see that the comparison is inconclusive. The magnitude of the tax change seems to matter. This may explain the noisy estimates for beer reported in table 7. For soda, on the other hand, the two tax changes, upward and downward, are of about the same magnitude.

Overall our results in table 7 suggest that the excise tax pass-through exceeds unity and that the pass-through of tax hikes exceeds that of tax cuts for soda. These results suggest that retailers may decide not to adjust prices downward in response to tax cuts to the same extent as they respond to tax hikes. Instead they keep prices unchanged and increase the profit margin. In case of a tax hike, they respond by increasing prices more than the tax change; our point estimates suggest very large overshifting. At the same time, the size of the tax change in relation to the unit price also matters. The tax pass-through tends to increase with the tax change relative to the unit price. This seems 
Table 7

Testing Asymmetric Excise Tax Pass-through: All Events, Beer and Soda

\begin{tabular}{lccc}
\hline & All beverages & Beer & Soda \\
\hline$\beta_{0}$ tax cut & $1.026^{* * *}$ & $7.679^{* * *}$ & $0.660^{* * *}$ \\
& $(0.014)$ & $(1.250)$ & $(0.221)$ \\
$\sum_{k=0}^{4} \beta_{k}$ tax cut & $1.022^{* * *}$ & $5.317^{* * *}$ & -0.095 \\
& $(0.014)$ & $(2.225)$ & $(0.631)$ \\
$\beta_{0}$ tax hike & {$[0.111]$} & {$[0.053]$} & {$[0.083]$} \\
& $2.378^{* * *}$ & -2.557 & $2.152^{* * *}$ \\
$\sum_{k=0}^{4} \beta_{k}$ tax hike & $(0.316)$ & $(1.771)$ & $(0.202)$ \\
& $3.132^{* * *}$ & $16.611^{* * *}$ & $2.618^{* * *}$ \\
& $(0.316)$ & $(5.409)$ & $(0.619)$ \\
Rent & {$[0.000]$} & {$[0.004]$} & {$[0.009]$} \\
\hline CPI & $-0.026^{* *}$ & $-0.431^{* * *}$ & $-0.099^{* *}$ \\
& $(0.011)$ & $(0.106)$ & $(0.049)$ \\
CPI ${ }^{2}$ & $-0.051^{* *}$ & $-0.257^{* * *}$ & 0.042 \\
& $(0.024)$ & $(0.070)$ & $(0.031)$ \\
Energy & 0.108 & $0.289^{* * *}$ & -0.031 \\
& $(0.073)$ & $(0.091)$ & $(0.072)$ \\
Labcost & 0.018 & -0.012 & 0.008 \\
& $(0.016)$ & $(0.012)$ & $(0.007)$ \\
Labcost ${ }^{2}$ & $0.040^{* * *}$ & $0.059^{* * *}$ & 0.026 \\
& $(0.007)$ & $(0.019)$ & $(0.024)$ \\
& $0.018^{* *}$ & $0.191^{* * *}$ & $-0.036^{*}$ \\
Adj. $R^{2}$ & $(0.008)$ & $(0.039)$ & $(0.019)$ \\
\# Groups & 0.920 & 0.022 & 0.333 \\
\# Obs. & 1508 & 775 & 595 \\
\# Obs. tax cuts & 15384 & 8778 & 4699 \\
\hline
\end{tabular}

Note: The table reports fixed-effects estimates of equation (2) including time effects. Robust and clustered (on goods) standard errors are reported within parentheses below each point estimate. $p$-values for tests of whether tax pass-through is equal during tax cuts and tax hikes are reported within brackets.

intuitive and is consistent with previous findings in Karp and Perloff (1989), Zápal (2014), and Conlon and Rao (2016). In our sample we find that large relative changes in the excise tax are associated with lower tax pass-through. For example, the tax increase on beer in 2005 was small in relation to the average pretax price, while the pass-through was very large. The tax cut on liquor in 2003 was large relative to the pretax price, and the tax change was undershifted. Looking more closely at each of our six tax events, it is clear that relatively large tax changes are associated with lower tax pass-through. Altogether, these results suggest that policymakers should be cautious not to 
change excise taxes by small amounts, at least if the goal is complete or close to complete tax pass-through.

\section{Border Effects}

One underlying argument used by the Danish government for cutting excise taxes on alcoholic and nonalcoholic beverages was to prevent and limit crossborder trade with Germany, where excise taxes are considerably lower. ${ }^{17}$ Historically, retail prices of soda have been very high in Denmark, much higher than in most other European countries, including Germany. We would therefore expect that the tax pass-through should become smaller as the distance to the German border decreases. In order to examine if this is the case, we run regressions similar to the ones presented in table 6 above, adding the distance to the German border measured in kilometers (the distance from the center of the zip code to the nearest town in Germany). In order to measure the effect of the distance to the German border on tax pass-through, we interact the natural logarithm of the distance and the change in the excise tax. As a consequence, the tax pass-through will now be a function of the distance. Note that distance is constant, i.e., not time-varying, for each beverage type $i$, implying that we cannot add all constitutive terms as we normally can when introducing interaction terms. Instead, these constant differences will be captured by the fixed effects. We estimate the following regression:

$$
\begin{aligned}
\Delta p_{i, j, t}=\sum_{k=0}^{4} \beta_{k} \Delta \tau_{i, t-k}+\sum_{k=5}^{8} \beta_{k} \Delta \tau_{i, t+5-k} \times \ln d i s t & +\alpha_{i}+\alpha_{t} \\
& +\sum_{k=1}^{N} \gamma_{k} X_{t}+\varepsilon_{i, t} .
\end{aligned}
$$

The results are shown in table 8 (analogous to table 6). Note that all control variables in our base model are included here as well - even the unobserved fixed and time effects, though they are not reported in the table. A striking result in the table is the lack of significant tax pass-through (except for beer) and the fact that the interaction terms are all insignificant. But, as is well known in the literature, the insignificance of constitutive terms may not reveal whether or not the tax pass-through as a function of distance, in our case, is significant. For this reason we report the pass-through for two cases: the minimum

17 See Bygvrå (1998) for a detailed description of cross-border trade between Denmark and Germany after the establishment of the Single European Market in 1993. For a more recent study of cross-border shopping, not only across the Danish-German border but also in other border regions, see Bygvrå (2018). 
Table 8

Testing German-Border Effects

\begin{tabular}{|c|c|c|c|c|}
\hline & All beverages & Beer & Soda & Liquor \\
\hline$\beta_{0}$ & $\begin{array}{c}1.435 \\
(0.922)\end{array}$ & $\begin{array}{c}4.856 * * \\
(1.970)\end{array}$ & $\begin{array}{c}0.195 \\
(1.002)\end{array}$ & $\begin{array}{c}1.211 \\
(1.028)\end{array}$ \\
\hline$\sum_{k=0}^{4} \beta_{k}$ & $\begin{array}{c}1.052 \\
(0.922)\end{array}$ & $\begin{array}{c}3.775 \\
(3.023)\end{array}$ & $\begin{array}{c}1.188 \\
(1.245)\end{array}$ & $\begin{array}{c}0.772 \\
(0.869)\end{array}$ \\
\hline$\beta_{5}$ & $\begin{array}{l}-0.076 \\
(0.196)\end{array}$ & $\begin{array}{c}0.301 \\
(0.373)\end{array}$ & $\begin{array}{c}0.295 \\
(0.192)\end{array}$ & $\begin{array}{l}-0.081 \\
(0.195)\end{array}$ \\
\hline$\sum_{k=5}^{8} \beta_{t-k}$ & $\begin{array}{l}-0.005 \\
(0.173)\end{array}$ & $\begin{array}{l}0.925^{*} \\
(0.506)\end{array}$ & $\begin{array}{c}0.234 \\
(0.236)\end{array}$ & $\begin{array}{l}-0.010 \\
(0.166)\end{array}$ \\
\hline Tax incidence at min distance & $\begin{array}{c}1.035 * * * \\
(0.285)\end{array}$ & $\begin{array}{c}7.177 * * * \\
(1.795)\end{array}$ & $\begin{array}{c}2.049 * * * \\
(0.419)\end{array}$ & $\begin{array}{c}0.734 * * * \\
(0.264)\end{array}$ \\
\hline Tax incidence at max distance & $\begin{array}{c}1.024 * * * \\
(0.103)\end{array}$ & $\begin{array}{c}9.242 * * * \\
(1.734)\end{array}$ & $\begin{array}{c}2.571 * * * \\
(0.270)\end{array}$ & $\begin{array}{c}0.711 * * * * \\
(0.135)\end{array}$ \\
\hline $\begin{array}{l}\text { Adj. } R^{2} \\
\text { \# Groups } \\
\text { \# Obs }\end{array}$ & $\begin{array}{c}0.921 \\
1507 \\
15377\end{array}$ & $\begin{array}{c}0.020 \\
775 \\
8778\end{array}$ & $\begin{array}{c}0.335 \\
594 \\
4692\end{array}$ & $\begin{array}{c}0.930 \\
138 \\
1907\end{array}$ \\
\hline
\end{tabular}

Note: The table reports fixed-effects estimates of equation (3) including time effects as well as all control variables used in regressions reported in table 6. Robust and clustered (on goods) standard errors are reported within parentheses below each point estimate. The distance is measured as the natural logarithm of the distance from the center of the zip code to the closest town in Germany, measured in kilometers. Tax incidences at min and max distances are the marginal effects of excise taxes measured at minimum and maximum distance from the German border.

and the maximum distance in our sample. To estimate the tax pass-through we set all other control variables equal to zero (we compute the partial derivative of the change in prices with respect to the excise tax change), i.e., the tax pass-through is computed as $\sum_{k=0}^{4} \beta_{k}+\sum_{k=5}^{8} \beta_{k} \times \ln d i s t$.

Turning to the results, we find that there are small and insignificant differences between the pass-through for retailers located close to the border and retailers located far away from the border when using the full data set. Distinguishing between types of beverages, our results reveal that distance is of importance for both beer and soda but not for liquor. The tax pass-through increases with distance to the German border for those two types of beverages. There is more overshifting at retailers located far away from the border. For example, comparing the tax pass-through on beer in Copenhagen (located $215 \mathrm{~km}$ from the German border) and in Nykøbing (located only $88 \mathrm{~km}$ from the German border), we find a significantly higher (at the 10-percent level) pass-through in Copenhagen (increasing from 4.2 to 5.0). For soda we find no significant difference in the pass-through between these two locations (point estimates increase from 1.0 to 1.3). To further illustrate these differences, we 
provide a graph of the marginal effects of distance on tax pass-through in figure 5. The figure clearly illustrates that the pass-through is increasing in distance. Since taxes and prices are substantially lower on all three types of beverages in Germany, we would expect a uniform and common pattern in our data. However, for liquor we find almost no difference in the pass-through; distance does not seem to matter. One reason for this may be that the size effect discussed above dominates: the fact that the size of the tax change on liquor exceeds the tax change on beer and soda and for that reason the tax pass-through is smaller. Overall, we find that the tax incidence on soda and beer is affected by proximity to the German border. In this regard, the official argument underlying these tax changes, in particular the tax cuts, is supported by empirical evidence.

\section{Figure 5}

Effect of (ln) Distance on Tax Pass-through for Beer and Soda
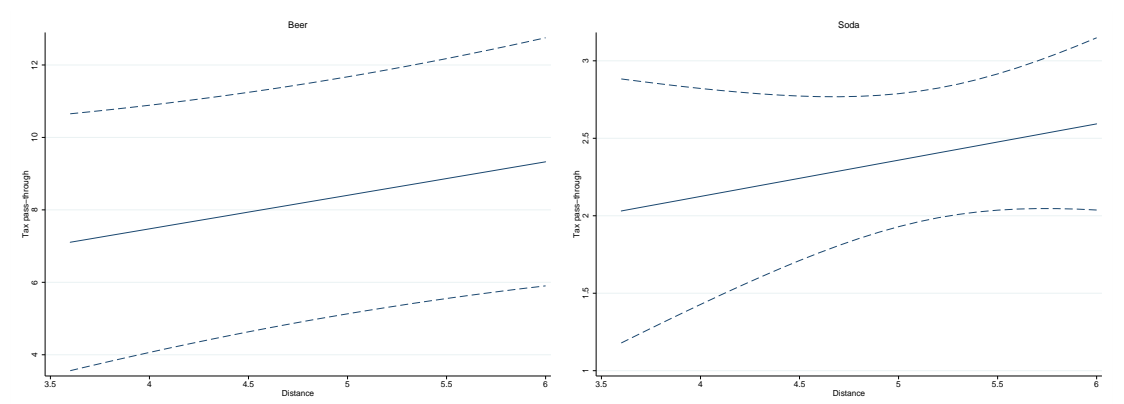

Note: Marginal effects of distance on tax pass-through, based on estimates in columns 2 and 3 in table 8 .

The empirical results discussed above suggested a significant difference in the tax pass-through between tax cuts and tax hikes. We reestimate the model in equation (3), adding dummy variables to distinguish between tax hikes and tax cuts as in equation (2). Figure 6 provides plots of the marginal effects of distance on the tax pass-through. It is clear that distance to the German border has different effects on the tax pass-through depending on the type of beverage and also on whether taxes are raised or lowered. Figure 6a shows the marginal effects of distance conditional on a tax cut. For stores located very close to the German border we find an insignificant tax pass-through. As the distance is increased, tax pass-through becomes statistically significant and increases from roughly 4 to 6 . The pattern is similar for tax hikes, but the pass-through is substantially larger and the marginal-effect curve is less steep. In both cases, distance is a complement in the tax pass-through. The response of soda prices 


\section{Figure 6}

Effect of (ln) Distance on Tax Pass-through for Beer and Soda, Distinguishing Between Tax Cuts and Tax Hikes

(a) Beer

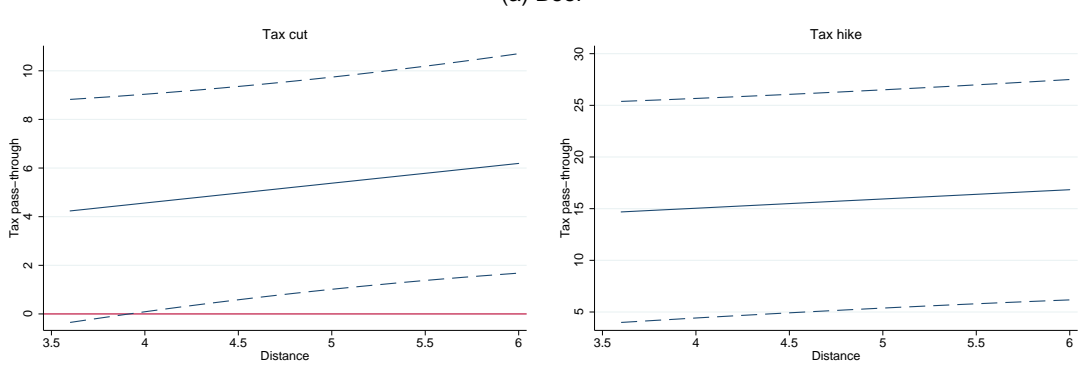

(b) Soda
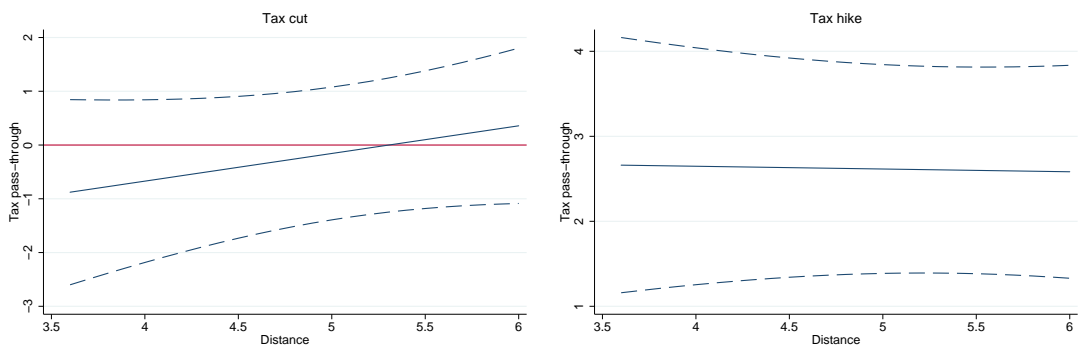

Note: Marginal effects of distance on tax pass-through, based on extended estimates in columns 2 and 3 in table 8 , where we distinguish between tax hikes and tax cuts.

is completely different. For tax cuts we find no significant marginal effect of distance, and for tax hikes we find no complementarity. In fact, the marginal effect is downward sloping, but there is no significant difference in the tax pass-through at minimum and maximum distances. Comparing beer and soda, we also note, as was also evident in our initial empirical tests, that the passthrough of tax hikes on beer is more than three times as large as on soda.

\section{Conclusions}

This paper has focused on excise tax shifting for alcoholic and nonalcoholic beverages in Denmark. Using micro data collected by Statistics Denmark, we estimate the excise tax pass-through on after-tax beverage prices during six tax events: three tax increases and three tax cuts. Our main finding is that excise taxes on beer and soda are overshifted to consumers, whereas we find undershifting for liquor. Considering the relative size of the tax change in rela- 
tion to the pretax price, it seems that small tax changes tend to be overshifted while larger tax changes are undershifted, as found earlier by Karp and Perloff (1989), Zápal (2014), and Conlon and Rao (2016). In the Danish case, the tax changes on beer and soda are very small (in the range from less than 1 percent to around 5 percent), whereas they were at least 30 percent for liquor, depending on the brand. However, there is a high degree of heterogeneity across chains of stores; for some chains we find overshifting, and in a few full shifting. There is also evidence suggesting asymmetric responses to tax cuts and tax hikes. We find that excise taxes are overshifted to a larger extent following tax hikes than following tax cuts on soda. It is unlikely that the size of the tax changes explains this finding, since the size of the tax cut on soda exceeds the size of the tax hikes.

Our empirical analysis also suggests that proximity to the German border affects the tax pass-through. Estimates for beer and soda suggest that the tax pass-through is increasing in the distance to the border. Higher competition from border trade makes retailers more inclined to limit price changes when excise taxes change, particularly when there is a tax hike. Surprisingly, our results also suggest that distance has no significant effect on soda prices following a tax cut.

These findings are consistent with recent studies of SSBs implemented in Berkeley (Falbe et al., 2015; Falbe et al., 2016; Crowley and Frisvold, 2017) suggesting undershifting, and in Mexico (Grogger, 2017) suggesting overshifting. The tax change relative to the base price is larger in Berkeley than in Mexico. For beer, our findings are consistent with previous results, which very often but not always find overshifting. A striking difference between our results and what is found in the previous literature is that we find undershifting of excise taxes on liquor. A possible explanation is that the tax change on liquor in Denmark was much larger in relation to the base price than in other countries.

The finding that the response is either undershifting or overshifting is consistent with the market conditions in the retail sector in Denmark. The market is segmented, and it is likely that retailers can deviate from market prices even though they at the same time compete over customers. A distinguishing feature of the retail market is that there are many small supermarkets located close to each other and very few large supermarkets. Most supermarkets sell all three types of beverages that we focus on in this paper, and it is surprising that the tax pass-through differs across the three different types of beverages. However, the size of the tax change in relation to the pretax price could explain why we find different results for the three types of beverages. 
U. Michael Bergman and Niels Lynggård Hansen

\section{Appendix: Tax Pass-through Conditional on Disposable Income}

Table 9

Estimates of Excise Tax Pass-through for Each Type of Beverage, Conditional on Disposable Income

\begin{tabular}{lcccc}
\hline & All beverages & Beer & Soda & Liquor \\
\hline$\beta_{0}$ & $1.022^{* * *}$ & -0.519 & $2.036^{* * *}$ & $0.813^{* * *}$ \\
& $(0.015)$ & $(1.089)$ & $(0.245)$ & $(0.083)$ \\
& {$[0.139]$} & {$[0.164]$} & {$[0.000]$} & {$[0.027]$} \\
$\sum_{k=0}^{4} \beta_{k}$ & $-1.229 * *$ & 0.180 & $3.450^{* * *}$ & $0.784^{* * *}$ \\
& $(0.523)$ & $(1.524)$ & $(0.919)$ & $(0.077)$ \\
& {$[0.000]$} & {$[0.591]$} & {$[0.008]$} & {$[0.006]$} \\
Rent & -0.029 & 0.128 & 0.063 & $121.282^{* *}$ \\
& $(0.024)$ & $(0.124)$ & $(0.050)$ & $(53.967)$ \\
CPI & 0.079 & 0.038 & 0.022 & $-11.954 * *$ \\
& $(0.070)$ & $(0.090)$ & $(0.670)$ & $(4.005)$ \\
CPI ${ }^{2}$ & $-0.241^{* *}$ & -0.042 & -0.124 & $29.577 * * *$ \\
& $(0.107)$ & $(0.068)$ & $(1.542)$ & $(8.250)$ \\
Energy & $0.139 * *$ & 0.017 & -0.109 & $7.665 * * *$ \\
& $(0.055)$ & $(0.016)$ & $(0.090)$ & $(2.736)$ \\
Labcost & $0.077 * * *$ & -0.008 & 0.033 & Omitted \\
& $(0.014)$ & $(0.022)$ & $(0.097)$ & \\
Labcost ${ }^{2}$ & $-0.187 * * *$ & -0.030 & 0.037 & Omitted \\
& $(0.047)$ & $(0.046)$ & $(0.175)$ & \\
Income & 0.987 & -0.145 & 0.755 & Omitted \\
& $(0.934)$ & $(0.623)$ & $(0.756)$ & \\
Adj. $R^{2}$ & 0.940 & 0.018 & 0.377 & 0.944 \\
\# Groups & 988 & 355 & 505 & 128 \\
\# Obs & 7696 & 3868 & 3194 & 634 \\
\hline
\end{tabular}

Note: "Income" is the natural logarithm of annual disposable income in different regions defined using zip codes matched to zip codes associated with the location of stores. The table reports fixed-effects estimates of equation (1) including time effects. Robust and clustered (on goods) standard errors are reported within parentheses below each point estimate. $p$-values of tests of full tax pass-through (that the contemporaneous or total tax pass-through is equal to unity) are reported within brackets.

\section{References}

Alm, J., Sennoga, E., and Skidmore, M. (2009), Perfect Competition, Urbanization, and Tax Incidence in the Retail Gasoline Market, Economic Inquiry 47, 118-134.

Anderson, S. P., de Palma, A., and Kreider, B. (2001), Tax Incidence in Differentiated Product Oligopoly, Journal of Public Economics 81, 173-192. 
Baker, P., and Brechling, V. (1992), The Impact of Excise Duty Changes on Retail Prices in the UK, Fiscal Studies 13, 48-65.

Berardi, N., Sevestre, P., Tepaut, M., and Vigneron, A. (2016), The Impact of a 'Soda Tax' on Prices. Evidence from French Micro Data, Applied Economics 48, 3976-3994.

Besley, T. (1989), Commodity Taxation and Imperfect Competition: A Note on the Effects of Entry, Journal of Public Economics 40, 359-367.

Besley, T. J., and Rosen, H. S. (1999), Sales Taxes and Prices: An Empirical Analysis, National Tax Journal 52, 157-178.

Bygvrå, S. (1998), The Road to the Single European Market as seen through the Danish Retail Trade: Cross-Border Shopping between Denmark and Germany, International Review of Retail, Distribution and Consumer Research 8, 147-164.

Bygvrå, S. (2018), Cross-Border Shopping: Just Like Domestic Shopping? A Comparative Study, GeoJournal 84, 497-518.

Carbonnier, C. (2007), Who Pays Sales Taxes? Evidence from French VAT Reforms, 1987-1999, Journal of Public Economics 91, 1219-1229.

Carbonnier, C. (2013), Pass-Through of Per Unit and ad Valorem Consumption Taxes: Evidence from Alcoholic Beverages in France, B.E. Journal of Economic Analysis \& Policy 13, 837-863.

Cawley, J., and Frisvold, D. (2017), The Incidence of Taxes on Sugar-Sweetened Beverages: The Case of Berkeley, California, Journal of Policy Analysis and Management 36, 303-326.

Chouinard, H., and Perloff, J. M. (2004), Incidence of Federal and State Gasoline Taxes, Economics Letters 83, 55-60.

Conlon, C. T., and Rao, N. S. (2016), Wholesale Prices, Retail Prices and the Lumpy Pass-Through of Alcohol Taxes, Columbia University Working Paper.

Danish Competition and Consumer Authority (2011), Dagligvaremarkedet, Konkurrence- og Forbrugeranalyse 06/2011.

DeCicca, P., Kenkel, D., and Liu, F. (2013), Who Pays Cigarette Taxes? The Impact of Consumer Price Search, Review of Economics and Statistics 95, 516-529.

Delipalla, S., and Keen, M. (1992), The Comparison Between Ad Valorem and Specific Taxation under Imperfect Competition, Journal of Public Economics 49, 351-367.

Delipalla, S., and O’Donnel, O. (2001), Estimating Tax Incidence, Market Power and Market Conduct: The European Cigarette Industry, International Journal of Industrial Organization $19,885-908$.

Doyle Jr., J. J., and Samphantharak, K. (2008), \$2.00 Gas! Studying the Effects of a Gas Tax Moratorium, Journal of Public Economics 92, 869-884.

Einarsson, A. (2008), The Retail Sector in the Nordic Countries: A Description of the Differences, Similarities, and Uniqueness in the Global Market, Journal of Retailing and Consumer Services 15, 443-451.

Falbe, J., Rojas, N., Grummon, A. H., and Madsen, K. A. (2015), Higher Retail Prices of Sugar-Sweetened Beverages 3 Months After Implementation of an Excise Tax in Berkeley, California, American Journal of Public Health 105, 2194-2201.

Falbe, J., Thompson, H. R., Becker, C. M., Rojas, N., McCulloch, C. E., and Madsen, K. A. (2016), Impact of the Berkeley Excise Tax on Sugar-Sweetened Beverage Consumption, American Journal of Public Health 106, 1865-1871.

Formby, J. P., Layson, S., and Smith, W. J. (1982), The Law of Demand, Positive Sloping Marginal Revenue, and Multiple Profit Equilibria, Economic Inquiry 20, 303-311. 
Grogger, J. (2017), Soda Taxes and the Prices of Sodas and Other Drinks: Evidence from Mexico, American Journal of Agricultural Economics 99, 481-498.

Hamilton, S. F. (2008), Excise Taxes with Multiproduct Transactions, American Economic Review 99, 458-471.

Hansen, N. L., and Hansen, B. W. (2007), Price Setting Behaviour in Denmark: A Study of CPI Micro Data 1997-2005, Danish Journal of Economics 145, 29-58.

Harding, M., Leibtag, E., and Lovenheim, M. (2012), The Heterogeneous Geographic and Socioeconomic Incidence of Cigarette and Beer Taxes: Evidence from Nielsen Homescan Data, American Economic Journal: Economic Policy 4, 169-198.

Karp, L. S., and Perloff, J. M. (1989), Estimating Market Structure and Tax Incidence: The Japanese Television Market, Journal of Industrial Economics 37, 225-239.

Katz, M. L., and Rosen, H. S. (1985), Tax Analysis in an Oligopoly Model, Public Finance Quarterly 13, 3-19.

Kenkel, D. S. (2005), Are Alcohol Tax Hikes Fully Passed Through to Prices? Evidence from Alaska, American Economic Review 95, 273-277.

Nakamura, E., and Steinsson, J. (2008), Five Facts about Prices: A Reevaluation of Menu Cost Models, Quarterly Journal of Economics 123, 1415-1464.

Poterba, J. M. (1996), Retail Price Reactions to Changes in State and Local Sales Taxes, National Tax Journal 49, 165-176.

Shrestha, V., and Markowitz, S. (2016), The Pass-Through of Beer Taxes to Prices: Evidence from State and Federal Tax Changes, Economic Inquiry 54, 1946-1962.

Stehr, M. (2007), The Effect of Sunday Sales Bans and Excise Taxes on Drinking and Cross-Border Shopping for Alcoholic Beverages, National Tax Journal 60, 85-105.

Stern, N. (1987), The Effects of Taxation, Price Control and Government Contracts in Oligopoly and Monopolistic Competition, Journal of Public Economics 32, 133-158.

Young, D. J., and Bielińska-Kwapisz, A. (2002), Alcohol Taxes and Beverage Prices, National Tax Journal 55, 57-73.

Zápal, J. (2014), Consumption Tax Incidence: Evidence from the Natural Experiment in the Czech Republic, ACTA VSFS 8, 149-166. 
Dies ist urheberrechtlich geschütztes Material. Bereitgestellt von: CBS Library, 13.08.2020 